\title{
On the Possibility of Preferred Performance Styles and Their Link to Learning Styles
}

\author{
Krassimir Yankulov* and Rui Ray Lu \\ Department of Molecular and Cellular Biology, College of Biological Science, University of Guelph, Guelph, ON, Canada
}

\section{OPEN ACCESS}

Edited by:

Jesus de la Fuente,

University of Almería, Spain

Reviewed by:

Katie Zhukov,

The University of Queensland, Australia

Thomas James Lundy, Cuttlefish Arts, United States

*Correspondence: Krassimir Yankulov yankulov@uoguelph.ca

Specialty section:

This article was submitted to Educational Psychology,

a section of the journal

Frontiers in Education

Received: 16 March 2017 Accepted: 22 June 2017 Published: 10 July 2017

Citation:

Yankulov K and Lu RR (2017) On the Possibility of Preferred Performance Styles and Their Link to Learning

Styles.

Front. Educ. 2:32.

doi: 10.3389/feduc.2017.00032
The existence of individual learning styles is a hot topic in contemporary education theory and practice. There is an ongoing debate on whether learners benefit from teaching methods that are tailored to their perceived learning styles. The majority of educators believe that such styles do exist and a striving industry benefits from this concept. However, experts conclude that the evidence on this matter provides no support for the utility of learning styles. In this manuscript, we briefly review this debatable topic and focus on a key flaw in the analyses of learning styles. We indicate that the current models for the evaluation of such styles call for different instruction methods and a uniform test. However, the possibility that learner styles correlate to different performance in different types of examination has not been experimentally addressed. We discuss this discrepancy and propose methodologies that can identify such preferred performance styles.

Keywords: learning styles, teaching and learning models, teaching approaches, meshing hypothesis, performance assessment, performance evaluation

\section{LEARNING STYLES}

The notion of preferred learning styles is an important topic in the field of education (DiBartola et al., 2001; Coffield et al., 2004; Hawk and Shah, 2007; Leite et al., 2010; Evans and Vermunt, 2013). The concept is based on several theories, which postulate individual differences in the efficiency with which people learn and/or process different types of information [for a detailed review, see Coffield et al. (2004)]. It is believed that these differences shape the overall preferred learning style of an individual. It is, therefore, suggested that learners will most efficiently acquire new knowledge and skills if they employ learning strategies that fit their preferred learning styles. Further to that, proponents of the learning style theory maintain that optimal instruction is provided by means, which closely match the learning styles of the students and that teaching methods need to be preceded by the assessment of such learning styles and accordingly tailored to them. Consequently, several learning styles have been defined to reflect the means of instruction to which a learner would most efficiently respond and classifications of learning styles have been introduced. Some of the most popular, but by far not the only classifications include visual, auditory, and kinesthetic (VAK) and visual, auditory, read/write, and kinesthetic (VARK) (Anderson, 2016; Ford et al., 2016; Hughes, 2016; Maseleno et al., 2016). Other classifications of learning styles are provided in Table 1. All learning style theories and classifications postulate that learners will respond better to a teaching style that is aligned with their learning style. However, strong evidence in support of this hypothesis is yet to be obtained. 
TABLE 1 | Examples of classifications of learning styles and their commercialization.

http://www.learning-styles-online.com

https://teach.com

http://www.educationplanner.org

http://vark-learn.com

http://www.sgibson.k12.in.us/gshs_new/Gidcumb/Assignemt_1_Learning_

Style_Inventroy.pdf

http://carla.umn.edu/maxsa/documents/LearningStyleSurvey_MAXSA_IG.pdf

http://www.about.com/education

http://www.learningrx.com/types-of-learning-styles-faq.htm

http://www.edudemic.com/styles-of-learning

https://www.engr.ncsu.edu/learningstyles/ilsweb.html

https://www.uwo.ca/sdc/learning/index.html

https:/uwaterloo.ca/center-for-teaching-excellence/teaching-resources/

teaching-tips/tips-students/self-knowledge/understanding-your-learning-style

Examples form several university web pages and several commercial companies are presented. Only a small sample of the available classifications and questionnaires are listed.

\section{PROS AND CONS TO THE IDEA OF LEARNING STYLES}

\section{Pros}

The concept of learning styles is very popular. It is intuitive that individuals differ in their cognitive skills and their approaches to learning. It is also conceivable and that some learners would be more comfortable with one teaching style as compared to another. In support, extensive recent surveys have found that about $95 \%$ of teachers and educators with diverse backgrounds have agreed that indeed there are learning styles and that students learn better if instructed in their preferred style (Dekker et al., 2012; Howard-Jones, 2014; Willingham et al., 2015). Following this popularity, various educational institutions and companies advertise programs and inventories to address how to profile individual learning styles and how to accordingly improve teaching and learning practices. Several examples are shown in Table 1. Even more, these ideas have been successfully commercialized to advise companies and educators on how to tailor their instruction to the learning styles of the students (Table 1). This striving industry is offering guidebooks and professional workshops to enhance the efficacy of education based on the successful application of the learning style theory.

\section{Cons}

At the same time, the theory of learning styles has received strong criticism. Many educators, including the authors of the current manuscript, believe that that the key challenge to the theory is the lack of high-quality scientific evidence that adequately validates a link between the preferred learning styles and the corresponding teaching style (Coffield et al., 2004; Pashler et al., 2008; Rohrer and Pashler, 2012). Some authors go as far as completely denouncing the validity of the theory and placing the learning styles in the league of "neuromyths" (Howard-Jones, 2014; Weale, 2017). The uncertainty surrounding the theory of learning styles has recently spilled over to mass media publications (Busch, 2016; Hood et al., 2017; Weale, 2017) and into heated discussions on social networks (https://twitter.com/hashtag/vakoff?src=hash SPACE).
In an attempt to resolve the apparent discrepancy between the popularity of the concept of learning styles and its scientific foundation, Pashler et al. (2008) have outlined several criteria that would establish a sound evidence-based link between the learning styles and the learning outcomes. The authors have postulated that students with a specific learning style should achieve the best educational outcome when a specific matching instructional method is given, and that this particular instructional method differs from the instructional method that would produce the best outcome for students with a different learning style. This so-called meshing hypothesis is best illustrated by the graphic representation in Figure 1A. For example, students with a preferred visual learner style would achieve better outcomes when instructed by visual teaching means as compared to the outcomes when the same students are taught by auditory means. At the same time, learners with a preferred auditory style would achieve better outcomes when instructed by an auditory teaching style relative to a visual teaching style. So far, only one follow-up experimental study has used the proposed methodology and has analyzed the learning outcomes of two groups of students who were instructed by visual or auditory $(\mathrm{V}, \mathrm{A})$ means (Rogowski et al., 2015). Briefly, college-educated adults were asked to fill-in a questionnaire that determine their preferred learning styles. The participants were then randomly split in two groups and received the same instructional material by a digital audiobook or by e-text and then examined by a uniform written test. The study failed to obtain a clear distinction of learning outcomes based on the preferred learning styles and provided no evidence in favor of the hypothesis that learners benefit from instructions tailored to their learning style. Instead, the results showed that visual learners scored higher than auditory learners regardless of the instruction approach (Rogowski et al., 2015) (Figure 1B). A less rigorous study has obtained similar results (Yankulov, 2014). Nevertheless, in both studies, the authors have acknowledged that the issue of whether visual learners perform better in a written test has not been addressed.

In summary, despite the significant popularity of the concept, the utility of individual learning styles has not been adequately supported by evidence-based research.

\section{IS THERE A PREFERRED PERFORMANCE STYLE?}

Compared to learning styles, the topic of individual differences in performance and their link to learning outcomes has not been explored. We often hear that some students perform better in multiple choice questions than in short answer question or in essay assignments, and that some students clearly outperform others in oral or poster presentations. It appears that, in addition to specific learning styles, students may also have preferred performance styles, but this possibility remains largely unaddressed by research or theories. Importantly, the possibility of preferred performance styles also ties to the question of the utility of the preferred learning styles. For example, the proposed evaluation of learning styles (Pashler et al., 2008) calls for a uniform test regardless of the perceived learning preferences and teaching 
A Acceptable evidence for the learning-style hypothesis (modified from Pashler et al., 2008)

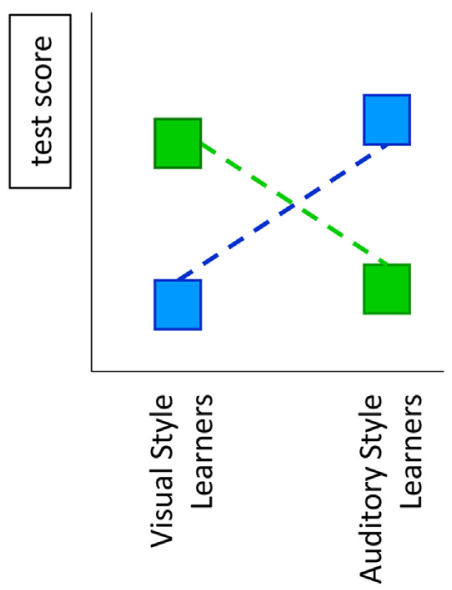

B Current evidence for the learningstyle hypothesis

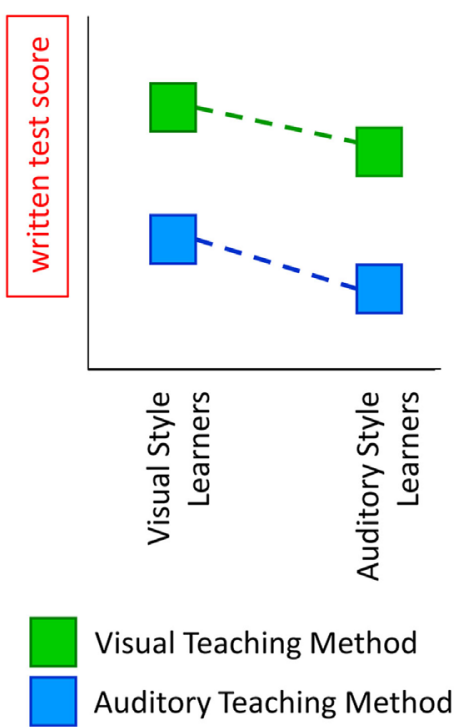

FIGURE 1 | Schematic representation of learning styles. (A) A diagram representing an acceptable evidence in favor of the learning style hypothesis. Students with one learning style should achieve the best educational outcome when given an instructional method that differs from the instructional method producing the best outcome for students with a different learning style. The diagram is modified from Pashler et al. (2008). For consistency with other figures, the two selected learning styles are Visual and Auditory. The hypothetical results from a uniform test for the Visual and Auditory learners are depicted by green and blue squares, respectively. (B) A diagram representing the outcome of the test of the learning style hypothesis. Students have been instructed by Visual or Auditory means and tested by a uniform written (W) test. The results of such studies showed that in a written test the Visual learners outperformed the Auditory-learners regardless of the means of instruction.

styles. In the only systematic experimental study that has directly tested the meshing hypothesis, these tests have been written exams (Rogowski et al., 2015). However, it is possible that visual learners perform better at written exams and auditory learners perform better at presentations or at on-line quizzes and questionnaires. This possibility is illustrated in Figure 2A. For convenience, the performance styles are named $\mathrm{W}$ (writing) and A (auditory). So, if there are differences in the performance styles of the learners, the findings in Yankulov (2014) and Rogowski et al. (2015) need to be re-evaluated. For example, the scenario depicted in Figure 2B represents the possible link between learning styles and learning outcomes as assessed by two different types of test. According to this more complex scenario, evidence in support of the learning-style hypothesis could be obtained using exactly the same methodology as in Rogowski et al. (2015) but with two examination methods. Hence, before we properly address the utility of learning styles, we need to have a clear idea about the contribution of the perceived performance styles to the evaluation of the learning styles. Equally important is the possibility of individual performance styles, which deserves attention on its own.

\section{Methodologies That Address the Possibility of Preferred Performance Styles}

In this manuscript, we propose and articulate two methodologies that can address the question of whether learners have preferred performance styles and if these preferences align with the postulated preferred learning styles.

\section{Methodology I: Data Collection in Existing Courses}

The core of the first methodology is to acquire broad-spectrum data from existing courses and fit these data to the predefined model in Figure 2B. Ideally, the proposed methodology will be initiated in large first/second year university courses that deliver course contents in several different formats-lectures, seminars, additional readings, and group assignments. A good example of such mixture of teaching styles can be found in the first year courses described in Husband et al. (2015). The performance of students in such courses is assessed by a variety of methods (Husband et al., 2015). While written exams dominate in the overall learning outcomes evaluation, poster presentations and the participation in seminar discussions are also significant components. These assessment approaches can be tailored and can be deemed W (writing) and A (auditory) exams. In essence, such courses with diversified instruction and assessment methods should provide a direct and feasible means to address the issue of preferred performance styles without compromising the efficiency of education.

In the beginning of the courses, students will be polled by a questionnaire to self-identify if they have a preference to a certain type of exam. The preparation of this questionnaire is likely the key to the success of the whole experiment. Experienced instructors and psychology experts should be involved at this initial stage. Separately, the students will be asked to respond to a questionnaire that profiles their preferred learning styles. One of the broadly used questionnaires for learning styles, for example the VARK questionnaire in http://vark-learn.com/ 


\section{A Acceptable evidence for the performance-style hypothesis}
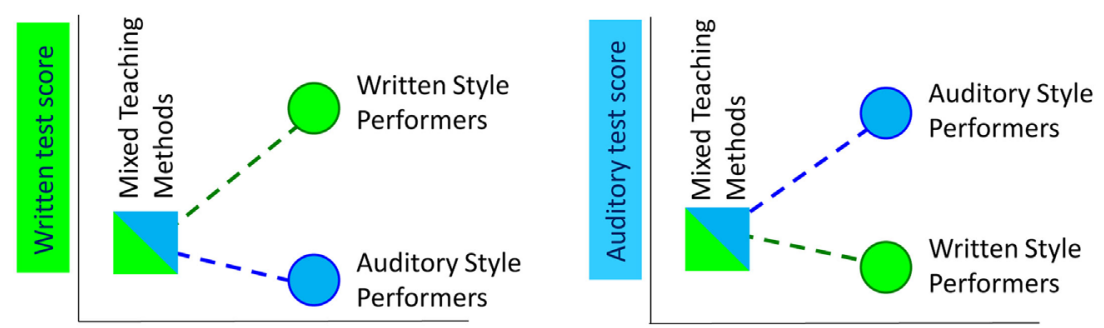

B Acceptable evidence for a link between learning and performance styles

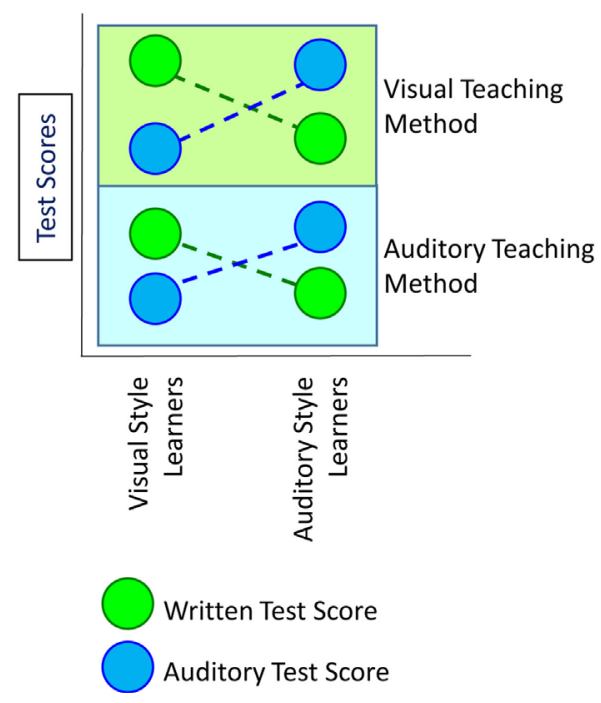

FIGURE 2 | Schematic representation of a hypothetical link between learning and performance styles. (A) Representation of the performance style hypothesis. In this scenario, students have been instructed by a mixture of teaching styles (Visual) and Auditory as shown by the green and blue colors in the rectangle and tested by two different methods (written, left panel and auditory, right panel). In this situation, the performance of students depends on the test method and not on the method of instruction. (B) Representation of the link between teaching and performance styles. Figure 1A is modified to reflect the possibility that test scores reflect the preferred performance style rather than the preferred learning style of the participants. While the range of scores may vary depending on the teaching method (Visual and Auditory as shown in the large green and blue rectangles), Visual learners outperform Auditory learners in written tests and Auditory learners outperform Visual learners in auditory tests.

the-vark-questionnaire, is an adequate source for the purposes of the proposed methodology.

After the establishment of the learning and performance preferences of the participants, two key analyses will be conducted. The first simple analysis will determine if students who have identified their preferred performance styles as W and A score equally well (or not) in the W and A type of assessments. Acceptable evidence in support of the performance style hypothesis will be obtained if the data fits to the model presented in Figure 2A. In essence, the expectation is that $\mathrm{W}$ students would perform better than A students in $\mathrm{W}$ exams and that the A students would perform better than $\mathrm{W}$ students in A exams. The second simple analyses would determine if students with self-identified $\mathrm{W}$ and A performance styles also distinguish themselves in terms of a preferred $\mathrm{W}$ and A learning styles. If this is the situation, it will be clear that an uniform written test does not properly address the question of the utility of learning styles and that the recent analyses on this issue (Yankulov, 2014; Rogowski et al., 2015) are not adequate.

The proposed approach has a foreseeable weakness. For example, the $\mathrm{W}$ and A tests may not be on the exactly same course material and that some variations in the results could be produced by the variations in the effectiveness with which students apprehend the material, regardless of their preferred learning styles. On the other hand, this approach provides a sufficiently broad base of analysis and the possibility of acquisition and comparison of data from different courses. Analyses can be performed for all participants in a given course and separately for the same participants in different courses. Ultimately, we expect that the large scope of this methodology and a sound statistical evaluation would contribute to its success. 


\section{Methodology II: Focused Experimental Assessment of Preferred Performance Styles}

Another test of the hypothesis of preferred performance styles is the use of a focused experimental set-up similar to the one described in Rogowski et al. (2015). For example, students again would be instructed by a mixture of visual and auditory $(\mathrm{V}, \mathrm{A})$ means. However, the assessment of the learning would be conducted by two parallel exams, $\mathrm{W}$ and $\mathrm{A}$, on the same material. The first exam could be an essay or a routine written test with short answers questions. The second exam could be a short presentation a poster, or an oral exam. Again, evidence in support of preferred performance styles would be obtained if these data fit the model presented in Figure 2A. This focused methodology calls for the allocation of additional resources for the two exams and large classes may not be suitable for such experiments. On the other hand, the methodology provides the means for a tightly controlled experiment with minimal variations in the contributing factors.

\section{Follow-Up Studies}

The follow-up studies need to obtain additional support to the idea of preferred performance styles. It will be essential to have independent lines of research in more than one university or in several colleges within a university. The data collection approach is applicable to such studies. In addition, the tracking of the performance of the participants in different assignments in lateryear classes could provide data on the persistence of performance styles during the course of education. For example, we can ask if performance styles are an acquired characteristic that will gradually diminish with the exposure to different style of exams at different university courses. The same question can be asked for preferred learning styles. Is it possible that the exposure to the various means of instruction would wane the preference for Visual of Auditory learner styles. This is another important and unaddressed variation in the theory of learning styles.

\section{Is There a Link between Preferred Learner and Performer Styles?}

So far, the proposed studies do not ultimately resolve the issue of whether learners benefit form teaching styles that are accordingly tailored to their preferred learner styles. A solid approach to address this question would be to conduct focused experiments similar to these in Rogowski et al. (2015). Two groups of students need to be instructed by two different teaching methods, for example Visual and Auditory. However, students should not be examined by a uniform written test. Instead, the two groups of

\section{REFERENCES}

Anderson, I. (2016). Identifying different learning styles to enhance the learning experience. Nurs. Stand. 31, 53-63. doi:10.7748/ns.2016.e10407

Busch, B. (2016). Four neuromyths still prevalent in schools debunked. The Guardian. Available at: https://www.theguardian.com/teacher-network/2016/ $\mathrm{feb} / 24 /$ four-neuromyths-still-prevalent-in-schools-debunked

Coffield, F., Moseley, D., Hall, E., and Ecclestone, K. (2004). Learning Styles and Pedagogy in Post-16 Learning: A Systematic and Critical Review. Learning \& Skills Research Centre: Report. London: Learning \& Skills Research Centre. students need to be examined by two types of exams (Written and Auditory) on the same material. An acceptable evidence in support of the hypothesis of correlated learning and performance styles would be obtained if these data fit the model presented in Figure 2B. The evidence will support the existence of learning styles but not performance styles if it fits the model in Figure 1A and in Pashler et al. (2008). Any other outcome would provide no evidence in support of the existence of learning styles.

Another useful approach to address the question of correlated learner and performance styles is to continue the data collection studies in existing university courses. For example, many senior courses emphasize teaching approaches that can be classified as Visual or Auditory or Kinesthetic. We can also identify written (an essay or a research proposal) or auditory (presentation, poster) type of assignments in such courses. The data on the performance of individual participants in this variety of different courses could deliver substantial circumstantial evidence that will again address the utility of learning styles.

\section{Concluding Remarks}

It is rather striking that an overwhelming majority of professional educators strongly believe in the benefits of learning styles while other experts point out that there is no scientific support for this idea and call it a "neuromyth" (Dekker et al., 2012; Howard-Jones, 2014; Willingham et al., 2015; Hood et al., 2017). While the lack of evidence in support of the theory of learning styles remains a major issue in the field, the same lack of evidence makes it is hard to go against the intuitive attitude of this many educators. Such an important issue needs to be properly resolved by evidence-based research before being dismissed or promoted. We assert that the current educational practices at many universities provide excellent means to analyze the links between preferred learning and performance styles.

\section{AUTHOR CONTRIBUTIONS}

$\mathrm{KY}$ and RL wrote the text and designed the figures. KY critically revised the manuscript and approved the final version.

\section{FUNDING}

$\mathrm{KY}$ and RL are professors at the Department of Molecular and Cellular Biology at the College of Biological Sciences at the University of Guelph, Canada. The authors acknowledge the College for fostering and promoting high educational standards and research in the field of university education.

Dekker, S., Lee, N. C., Howard-Jones, P., and Jolles, J. (2012). Neuromyths in education: prevalence and predictors of misconceptions among teachers. Front. Psychol. 3:429. doi:10.3389/fpsyg.2012.00429

DiBartola, L. M., Miller, M. K., and Turley, C. L. (2001). Do learning style and learning environment affect learning outcome? J. Allied Health 30, 112-115.

Evans, C., and Vermunt, J. D. (2013). Styles, approaches, and patterns in student learning. Br. J. Educ. Psychol. 83(Pt 2), 185-195. doi:10.1111/bjep.12017

Ford, J. H., Robinson, J. M., and Wise, M. E. (2016). Adaptation of the GrashaRiechman student learning style survey and teaching style inventory to assess 
individual teaching and learning styles in a quality improvement collaborative. BMC Med. Educ. 16:252. doi:10.1186/s12909-016-0772-4

Hawk, T. F., and Shah, A. (2007). Using learning style instruments to enhance student learning. J. Innovative Educ. 5, 1-19. doi:10.1111/j.1540-4609.2007.00125.x

Hood, B., Howard-Jones, P., Laurillard, D., Bishop, D., Coffield, F., Frith, D. U., et al. (2017). No evidence to back idea of learning styles. The Guardian. Available at: https://www.theguardian.com/education/2017/mar/12/no-evidence-to-backidea-of-learning-styles

Howard-Jones, P. A. (2014). Neuroscience and education: myths and messages. Nat. Rev. Neurosci. 15, 817-824. doi:10.1038/nrn3817

Hughes, G. (2016). Identifying learning styles. Nurs. Stand. 31, 72-73. doi:10.7748/ ns.31.16-18.72.s49

Husband, B., Bettger, W., Murrant, C., Kirby, K., Wright, P., Newmaster, S., et al. (2015). Applying a linked-course model to foster inquiry and integration across large first year course. Can. J. Higher Educ. 45, 244-260.

Leite, W. L., Svinicki, M., and Shi, Y. (2010). Attempted validation of the scores of the VARK: learning styles inventory with multitrait-multimethod confirmatory factor analysis models. Educ. Psychol. Meas. 70, 323-339. doi:10.1177/0013164409344507

Maseleno, A., Hardaker, G., Sabani, N., and Suhaili, N. (2016). Data on multicultural education and diagnostic information profiling: culture, learning styles and creativity. Data Brief 9, 1048-1051. doi:10.1016/j.dib.2016.11.024

Pashler, H., McDaniel, M., Rohrer, D., and Bjork, R. (2008). Learning styles: concepts and evidence. Psychol. Sci. Public Interest 9, 105-119. doi:10.1111/j.1539-6053.2009.01038.x
Rogowski, B., Calhoun, B., and Tallal, P. (2015). Matching learning style to instructional method: effects on comprehension. J. Educ. Psychol. 107, 64-78. doi:10.1037/a0037478

Rohrer, D., and Pashler, H. (2012). Learning styles: where's the evidence? Med. Educ. 46, 634-635. doi:10.1111/j.1365-2923.2012.04273.x

Weale, S. (2017). Teachers must ditch neuromyth of learning styles, scientist say. The Guardian. Available at: https://www.theguardian.com/education/2017/mar/13/ teachers-neuromyth-learning-styles-scientists-neuroscience-education

Willingham, D. T., Hughes, E. M., and Dobolyi, D. G. (2015). The scientific status of learning styles theories. Teach. Psychol. 42, 266-271. doi:10.1177/0098628315589505

Yankulov, K. (2014). More than spelling and grammar: students who prefer to write outperform students who prefer to present. Am. J. Educ. Res. 2, 1029-1035. doi:10.12691/education-2-11-5

Conflict of Interest Statement: The authors declare that the research was conducted in the absence of any commercial or financial relationships that could be construed as a potential conflict of interest.

Copyright (๑) 2017 Yankulov and Lu. This is an open-access article distributed under the terms of the Creative Commons Attribution License (CC BY). The use, distribution or reproduction in other forums is permitted, provided the original author(s) or licensor are credited and that the original publication in this journal is cited, in accordance with accepted academic practice. No use, distribution or reproduction is permitted which does not comply with these terms. 